\title{
Clinical Outcomes of Using Lasers for Peri-Implantitis Surface Detoxification: A Systematic Review and Meta-Analysis
}

James Mailoa, * Guo-Hao Lin, * Hsun-Liang Chan, ${ }^{*}$ Mark MacEachern, ${ }^{\dagger}$ and Hom-Lay Wang*

The aim of this systematic review is to compare the clinical outcomes of lasers with other commonly applied detoxification methods for treating peri-implantitis. An electronic search of four databases and a hand search of peer-reviewed journals for relevant articles were conducted. Comparative human clinical trials and case series with $\geq 6$ months of follow-up in $\geq 10$ patients with peri-implantitis treated with lasers were included. Additionally, animal studies applying lasers for treating peri-implantitis were also included. The included studies had to report probing depth (PD) reduction after the therapy.

Results: Seven human prospective clinical trials and two animal studies were included. In four and three human studies, lasers were accompanied with surgical and nonsurgical treatments, respectively. The meta-analyses showed an overall weighted mean difference of $0.00 \mathrm{~mm}$ (95\% confidence interval $=-0.18$ to $0.19 \mathrm{~mm}$ ) PD reduction between the laser and conventional treatment groups $(P=0.98)$ for non-surgical intervention. In animal studies, laser-treated rough-surface implants had a higher percentage of boneto-implant contact than smooth-surface implants. In a shortterm follow-up, lasers resulted in similar PD reduction when compared with conventional implant surface decontamination methods. J Periodontol 2014;85:1194-1202.

\section{KEY WORDS}

Decontamination; dental implants; lasers; laser therapy; meta-analysis; peri-implantitis.

\footnotetext{
* Graduate Periodontics, Department of Periodontics and Oral Medicine, School of Dentistry, University of Michigan, Ann Arbor, MI.

$\dagger$ A. Alfred Taubman Health Sciences Library, University of Michigan.
}

$\mathrm{P}$ eri-implantitis is an inflammatory process that affects both the hard and soft peri-implant tissues. ${ }^{1}$ It is characterized by progressive loss of supporting bone beyond biologic bone remodeling, and, if this is left untreated, it is very likely that peri-implantitis will lead to the failure of the affected implant. ${ }^{2}$ A number of risk factors have been identified that may lead to establishment and progression of peri-implantitis, including the following: 1) previous periodontal disease; 2) poor plaque control; 3) residual cement; 4) smoking; 5) genetic factors; 6) diabetes; and 7) occlusal overload. ${ }^{2}$ However, the American Academy of Periodontology white paper ${ }^{2}$ concluded that peri-implantitis is mainly initiated by the bacterial insult. The increases in proportions of the main periodontal pathogens, Porphyromonas gingivalis, Prevotella intermedia, Prevotella nigrescens, Tannerella forsythia, Treponema denticola, and Fusobacterium nucleatum, are associated with the occurrence of peri-implantitis. ${ }^{3,4}$ The pathogens form a biofilm that activates inflammatory cells, such as macrophages, neutrophil granulocytes, lymphocytes, and plasma cells. Activated immune cells release cytokines and enzymes that are harmful to host tissues. Plaque biofilm was reported to cover almost $60 \%$ of the infected implant surface. ${ }^{5}$ In addition, the biofilm adheres more strongly to rough implant surfaces than to smooth ones. ${ }^{6}$ These biofilms 
prohibit bone cells from reattaching to the implant surface. Therefore, when performing a surgical procedure, it is suggested to not only remove the inflamed tissue but also decontaminate the infected implant surfaces. ${ }^{7}$

Several implant decontamination methods have been proposed, including the following: 1) mechanical debridement; 2) chemical therapy; and 3) surgical procedures aimed at removing bacteria, smoothing implant surface, and decontamination/ detoxification of the implant surface using chemical agents or laser beam. ${ }^{8-10}$ A complete implant decontamination using mechanical and chemical procedures has been proven unsuccessful because of the following reasons: 1) limited access to implant microstructures; 2) the presence of resistant bacterial strains; 3 ) ineffective drug dosages ${ }^{11}$; and 4) inadequate bactericidal effect. ${ }^{12}$ Subsequently, application of lasers has been considered for decontamination of implant surfaces. Several in vitro and in vivo periodontal studies reported the effectiveness of erbium:yttrium-aluminum-garnet (Er:YAG) laser for root surface debridement. This type of laser not only effectively removed subgingival calculus but also showed excellent effects on soft and hard tissue ablation with strong bactericidal and photobiomodulation effects. ${ }^{13,14}$ Improved treatment outcomes could be expected because of the advantageous characteristics of lasers, such as their hemostatic effects, selective calculus ablation, and bactericidal effects against periodontal pathogens. ${ }^{15,16}$ Once the implant surface detoxification has been performed, it may be necessary to correct the anatomic defects with surgical interventions to improve plaque control and eliminate potential environments for anaerobic bacteria. ${ }^{17,18}$

Lasers with different wavelengths, which primarily determine tissue affinity and the degree of penetration, have been developed to optimize various clinical indications. ${ }^{19}$ For example, the energy emitted by the carbon dioxide $\left(\mathrm{CO}_{2}\right)$ laser is strongly absorbed by pure, homogeneous water and by biologic tissues high in water content. ${ }^{20}$ The Er:YAG laser is strongly absorbed by hydroxyapatite, for which it is efficient for hard tissue preparation. ${ }^{21}$ Because of the high bactericidal ability, the $\mathrm{CO}_{2}$ and Er:YAG lasers have also been used to decontaminate implants surfaces. ${ }^{10,22}$ The focused, monochrome light contains high energy that is lethal to bacteria. Inconsistencies in the literature existed regarding the clinical outcomes of the laser therapy for treating peri-implantitis. Therefore, the primary aim of this systematic review is to compare the clinical outcomes as a result of using laser therapy and other commonly applied methods for implant surface decontamination. The second aim is to identify a specific type of laser that resulted in superior clinical outcomes.

\section{MATERIALS AND METHODS}

\section{Selection Criteria and Search Strategy}

Both prospective and retrospective human clinical trials published in English from January 1980 to April 2013 were screened. To be included, studies had to adhere to the following inclusion criteria: 1) $\geq 10$ patients diagnosed with peri-implantitis and treated with lasers surgically or non-surgically; 2) a followup period of $\geq 6$ months; and 3 ) probing depth (PD) reduction reported after the therapy. Because of the limited number of human studies, preclinical studies with a follow-up period $\geq 6$ months were also included and analyzed separately from the human studies. The following were exclusion criteria: 1) studies published as editorials, letters, or comments and non-English citations; 2) simulating/in vitro studies; 3) review articles; and 4) case reports/series with $<10$ patients. The literature search was conducted by a health science librarian (MM). Four databases were searched: 1) Ovid MEDLINE; 2) PubMed; 3) EMBASE; and 4) Dentistry and Oral Sciences Source.

The search conducted in PubMed was as follows: ("peri-implantitis"[mesh] OR "peri-implant"[title/ abstract] OR "peri-implants"[title/abstract] OR "peri-implantitis" [title/abstract] OR peri-implant [title/abstract] OR periimplants[title/abstract] OR periimplantitis[title/abstract]) AND ("laser therapy"[mesh] OR "lasers, solid-state"[mesh] OR laser[title/abstract] OR lasers[title/abstract]) AND English[language] NOT (letter[publication type] OR comment[publication type] OR editorial[publication type]).

For the search in EMBASE, the search terms, in which $a b$ represented abstract and ti represented title, 'lim' represented limits, 'it' represented publication types, 'exp' represented explode, which expands a subject heading to include its related with more specific terms, were as follows: "peri-implantitis"/exp OR "peri-implant":ab,ti OR "peri-implants":ab,ti OR "peri-implantitis":ab,ti OR peri-implant*:ab,ti AND ("laser"/exp OR "solid state laser"/exp OR laser*:ab,ti) AND [english]/lim NOT ([animals]/lim NOT [humans]/ lim) NOT ("letter"/exp OR "editorial"/exp OR note:it OR erratum:it).

For searching in Dentistry and Oral Sciences Source, in which $\mathrm{AB}$ represented abstract, TI represented title, and SU represented subject terms. The search was as follows: (SU "PERI-implantitis" OR TI "peri-implant*" OR AB "peri-implant*") AND (SU "Lasers" OR TI "Laser*" OR AB "Laser*").

The search terms used for the search in Ovid MEDLINE are listed in supplementary Figure 1 in online Journal of Periodontology. 


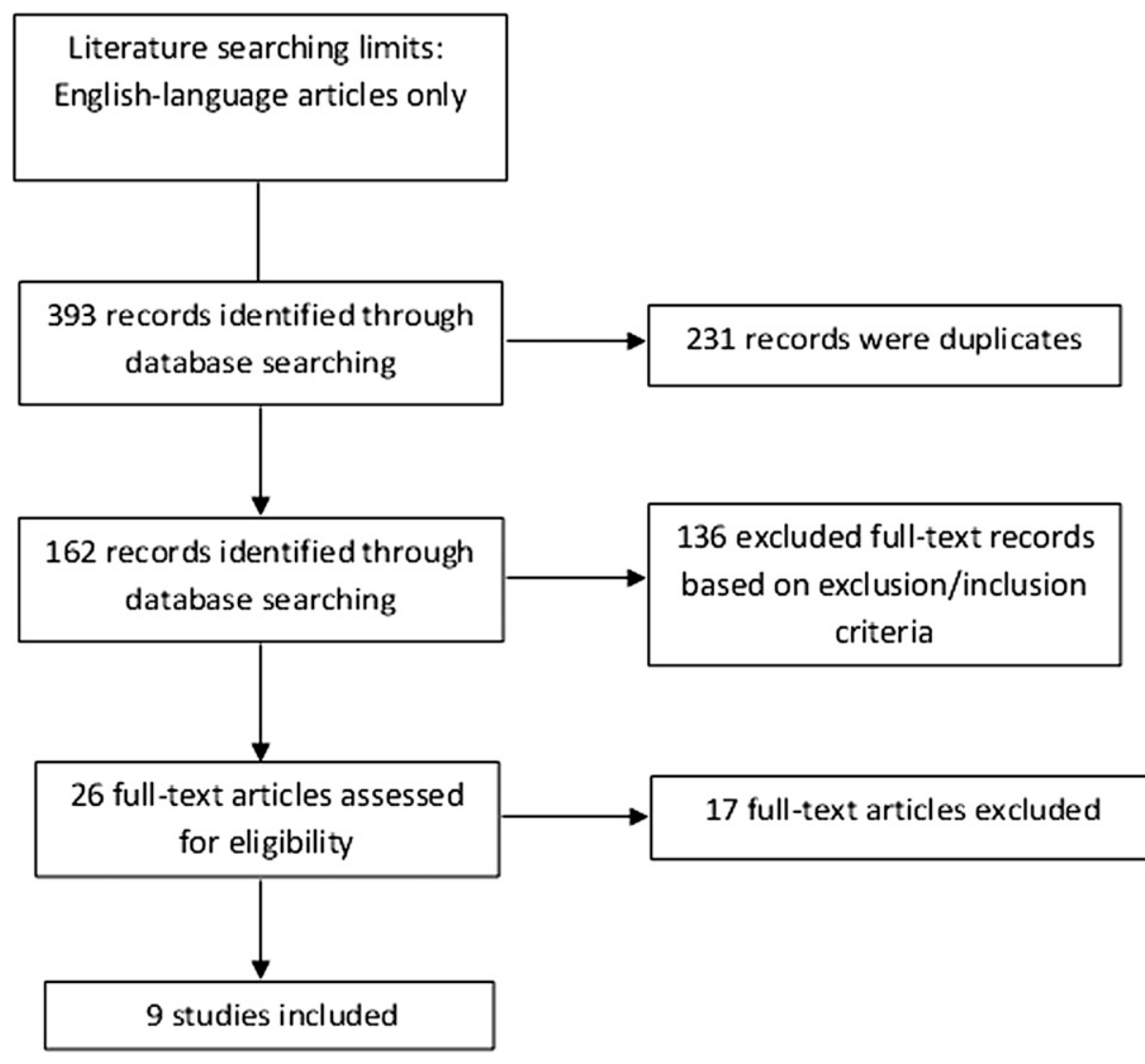

Figure 1 .

Flowchart of the screening process.

when only one criterion was missing; and 3) high risk if two or more criteria were missing.

\section{Data Analyses}

The primary outcome comprised the differences in PD reduction, and the secondary outcome comprised the changes of the other peri-implant parameters, including the clinical attachment level (CAL) gain, percentage of bleeding on probing (BOP) reduction, and radiographic bone gain. For comparative studies, the pooled weighted mean differences (WMDs) and the 95\% confidence interval $(\mathrm{CI})$ of each variable were calculated using a computer program. ${ }^{\ddagger}$ Random-effects meta-analyses of the selected studies were applied to avoid any biases caused by methodologic differences among studies. Forest plots were formulated to graphically represent WMD and 95\% $\mathrm{Cl}$ in primary and secondary outcomes for the included com-

A hand search was also performed for all offline journals (from January 1980 to April 2013). Furthermore, a search in the references of included papers, as well as the related systematic reviews, was conducted for publications that were not electronically identified. Potential articles were examined in full text by two reviewers (JM and H-LC), and their eligibility for this review was confirmed after discussion. The level of agreement between the reviewers regarding study inclusion was calculated with $\kappa$ statistics.

\section{Risk of Bias Assessment}

The following criteria modified from the randomized controlled trial (RCT) checklist of the Cochrane Center $^{23}$ and the CONSORT (Consolidated Standards of Reporting Trials) statement ${ }^{24}$ were used: 1 ) representative of general population; 2) allocation concealment method; 3) masking of the examiner; 4) intra/interexaminer calibration; 5) defined inclusions/exclusions; 6) participants drop-out, which indicated no loss of patient during follow-up period; and 7) analysis accounts for patient losses. The degree of bias was categorized as follows: 1) low risk if all the criteria were met; 2) moderate risk parative studies using the implant as the analysis unit. Heterogeneity was assessed with the $\chi^{2}$ test and the $I^{2}$ test, which ranges from $0 \%$ to $100 \%$, with lower values representing less heterogeneity. The reporting of the meta-analyses adhered to the PRISMA (Preferred Reporting Items for Systematic Review and Meta-Analyses) statement. ${ }^{25}$ In addition, the funnel plot was used to assess the presence of the publication bias.

\section{RESULTS}

The flowchart of the literature search is presented in Figure 1. The searches from the four databases yielded a total of 393 citations; after eliminating duplicates, 162 unique citations remained. After reviewing the titles and abstracts, 26 papers were further evaluated for eligibility with full text. Seventeen articles $5,8,26-40$ were excluded, and the reasons for exclusion are listed in supplementary Table 1 in online Journal of Periodontology.

The $\kappa$ value for interreviewer agreement for potentially relevant articles was 0.95 (titles and abstracts) and 0.99 (full-text articles), indicating

\footnotetext{
$\ddagger$ Review Manager (RevMan) v.5.0., The Nordic Cochrane Centre, The Cochrane Collaboration, Copenhagen, Denmark.
} 
an "almost perfect" agreement between the two reviewers according to the criteria of Landis and Koch. ${ }^{41}$ Nine papers (seven human clinical trials ${ }^{10,20,22,42-45}$ and two animal studies ${ }^{9,46}$ ) that met the inclusion criteria were included for data analyses.

\section{Human Clinical Trials}

Among the seven human clinical trials, ${ }^{10,20,22,42-45}$ lasers were used as an adjunct to surgeries in four studies; ${ }^{20,22,42,43}$ in the other three studies, ${ }^{10,44,45}$ lasers were used with a non-surgical approach. All surgical groups used bone grafting materials, including autografts, ${ }^{22,42}$ xenografts, ${ }^{22,43}$ and alloplasts. ${ }^{20}$ Membranes were also applied, including non-resorbable 20,42 and absorbable ${ }^{22,43}$ membranes. Most of the treated implants in the surgical groups were rough-surface implants, whereas smooth-surface implants were more commonly found in non-surgical laser-treated groups. All implants were treated with either $\mathrm{CO}_{2}{ }^{20,22}$ or Er:YAG ${ }^{10,43-45}$ lasers in the test groups. In the control groups, mechanical hand curettage with plastic curets $10,20,43$ or air abrasives $^{44,45}$ was applied. The follow-up period ranged from $9.5^{42}$ to $60^{20}$ months in the surgical groups and 6 months in all non-surgical groups. Patients showed a PD and BOP reduction and CAL gain when treated surgically or non-surgically. Higher mean PD reduction was generally achieved in the groups with augmentation using bone grafting materials and membranes. Comparable radiographic bone fill was observed in surgical treatment with lasers and hand instruments. ${ }^{20}$ When compared with conventional hand instrumentation, the lasertreated group failed to achieve higher PD/BOP reduction and CAL gain $(P>0.05)$ (Table 1$)$, except for in one study, ${ }^{10}$ which showed significantly more BOP reduction in the laser group with a non-surgical approach (Table 2).

\section{Animal Studies}

Of the two included animal studies, implants were placed bilaterally in four healthy beagle dogs to examine the efficacy of $\mathrm{CO}_{2}$ laser $^{9}$ and Er:YAG laser ${ }^{46}$ in the treatment of ligature-induced peri-implantitis. Flap surgeries were performed to decontaminate implant surfaces by means of laser (experimental groups) or mechanical instrumentation (control groups) without using any bone grafting and/or membrane materials. ${ }^{9,46} \mathrm{CO}_{2}$ laser achieved higher CAL gain in rough-surface implants than in smooth-surface implants. ${ }^{9}$ In addition, laser-treated rough-surface implants had a higher percentage of bone-to-implant contact than smooth-surface implants and control groups (Table 3). ${ }^{9,46}$ However, when compared with conventional hand instrumentation, no significantly superior outcomes were detected $(P>0.05)$ with the use of lasers. ${ }^{46}$

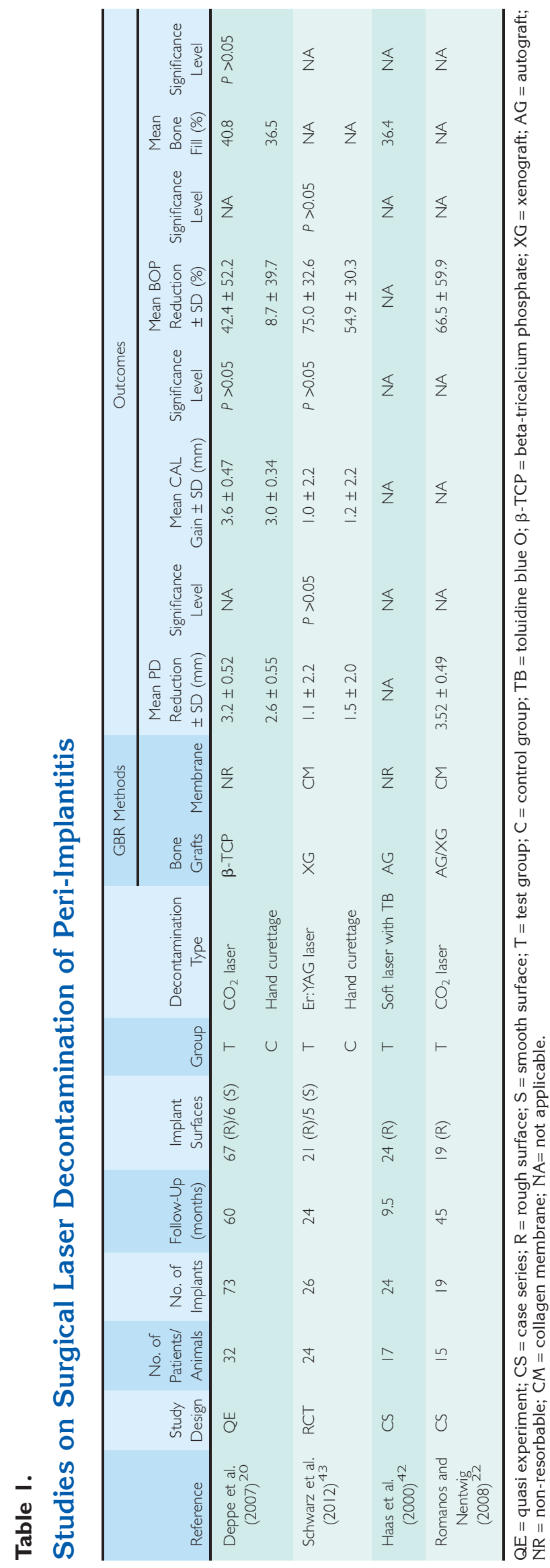



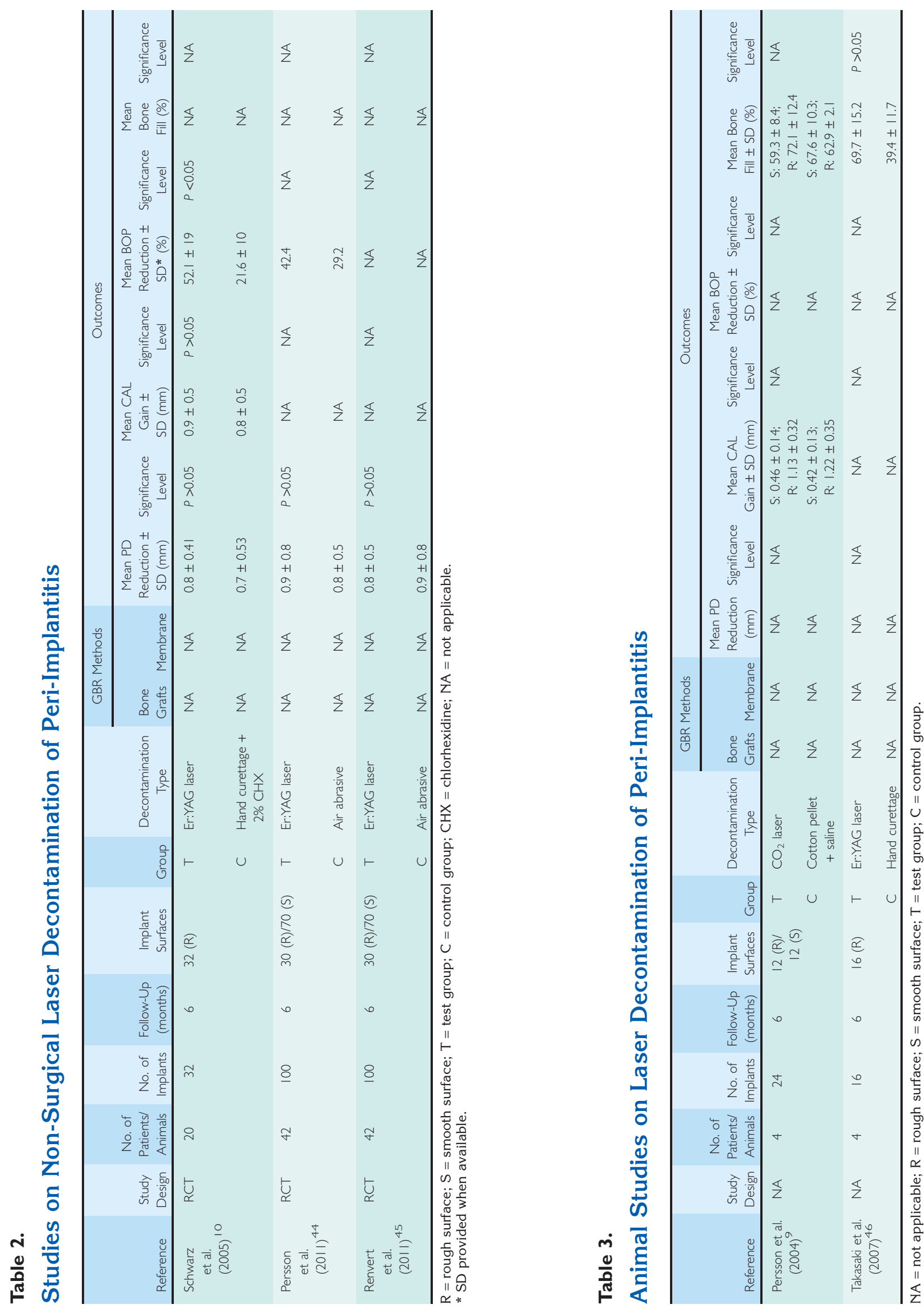


\section{Risk of Bias Assessment}

The results of risk of bias assessment for included RCTs are summarized in supplementary Table 2 in online Journal of Periodontology. Three studies ${ }^{10,43,44}$ had a low risk of bias, and one study ${ }^{45}$ was considered to have a moderate risk of bias. However, it is worth noting that only one $\mathrm{RCT}^{43}$ provided postoperative clinical photographs to demonstrate the stability of the peri-implant tissues. The other RCTs ${ }^{10,44,45}$ depicted the postoperative conditions in a descriptive manner.

\section{Results of the Meta-Analyses}

Data on PD reduction were provided in one $\mathrm{RCT}^{43}$ with surgical interventions and three RCTs ${ }^{10,44,45}$ with non-surgical interventions (Fig. 2). For surgical interventions, the WMD of PD reduction was -0.40 $\mathrm{mm}(95 \% \mathrm{Cl}=-2.09$ to $1.29 \mathrm{~mm}, P=0.64)$. For non-surgical interventions, the WMD was $0.00 \mathrm{~mm}$ $(95 \% \mathrm{CI}=-0.18$ to $0.19 \mathrm{~mm}, P=0.98)$. The comparisons presented a low heterogeneity among the selected studies with non-surgical interventions $\left(P\right.$ value for $\chi^{2}$ test $=0.58$ and $P$ test $\left.=0 \%\right)$. The results of the funnel plot presented a symmetrical distribution of included studies for PD reduction, indicating a potentially low risk of publication bias (see supplementary Fig. 2 in online Journal of Periodontology).

\section{DISCUSSION}

The present study found that only $\mathrm{CO}_{2}$ laser and Er:YAG laser were used in treating peri-implantitis lesions. The specifications of these lasers are summarized in Table 4 . This may be explained by the fact that these two types of lasers did not significantly increase implant body temperature during their application. ${ }^{37,47}$ Interestingly, neodymium: yttrium-aluminum-garnet (Nd:YAG) laser was not reported in any study; a possible explanation is that Nd:YAG laser ablates titanium irrespective of output energy. ${ }^{48}$ Similarly, the use of diode laser irradiation on implant surfaces showed increase of temperature above the critical threshold $\left(10^{\circ} \mathrm{C}\right)$ after only 10 seconds ${ }^{49}$ and was ineffective in removing calcified deposits. ${ }^{50}$ Therefore, Nd:YAG and diode lasers may be contraindicated for the treatment of periimplantitis because of increased temperature and the melting effect of titanium. ${ }^{48,49}$ Furthermore, bactericidal effects on textured implant surfaces were only reported for $\mathrm{CO}_{2}$ and Er:YAG lasers. ${ }^{51,52}$

In human clinical trials, all patients with periimplantitis showed reduction in PD and BOP when treated with lasers surgically or non-surgically. The reduction of PD and BOP scores in the laser group might be explained by the high bactericidal effect of lasers. ${ }^{37}$ Furthermore, several studies reported the antimicrobial effects against periodontopathic bacteria and the removal of lipopolysaccharides by laser radiation. ${ }^{13,53}$ However, when compared with conventional hand instrumentation, the lasertreated group failed to reveal higher $\mathrm{PD} / \mathrm{BOP}$ reduction and CAL gain. With regard to the promotion of radiographic bone fill, a previous study ${ }^{20}$ reported that $40 \%$ of bone fill was achieved when using $\mathrm{CO}_{2}$ lasers in combination with bone grafting material. It was also demonstrated that $\mathrm{CO}_{2}$ lasers possessed the ability to enhance bone regeneration when used as a detoxification tool in the treatment of experimentally induced peri-implantitis. ${ }^{30}$ The treatment modality for periimplantitis, which combined implant decontamination by means of soft laser and a photosensitizing substance with guided bone regeneration (GBR), has also been reported. ${ }^{42}$ The applied treatment concept was shown to be very effective, with $36.4 \%$ bone fill, for periimplant bony defects. However, all types of lasers exhibited a radiographic bone fill comparable with that of other commonly used surface detoxification methods. ${ }^{20,42,43}$

In the laser-treated group, meta-analyses showed no significant PD reduction when it was compared with the control

Figure 2.

Meta-analysis for PD reduction among selected studies. For surgical interventions, the WMD is $-0.40 \mathrm{~mm}$ $(95 \% \mathrm{Cl}=-2.09$ to $1.29 \mathrm{~mm}, \mathrm{P}=0.64)$. For non-surgical interventions, three $R C T$ s were included, and the WMD was $0.00 \mathrm{~mm}(95 \% \mathrm{Cl}=-0.18$ to $0.19 \mathrm{~mm}, \mathrm{P}=0.98)$. $\mathrm{QE}=$ quasi experiment. 


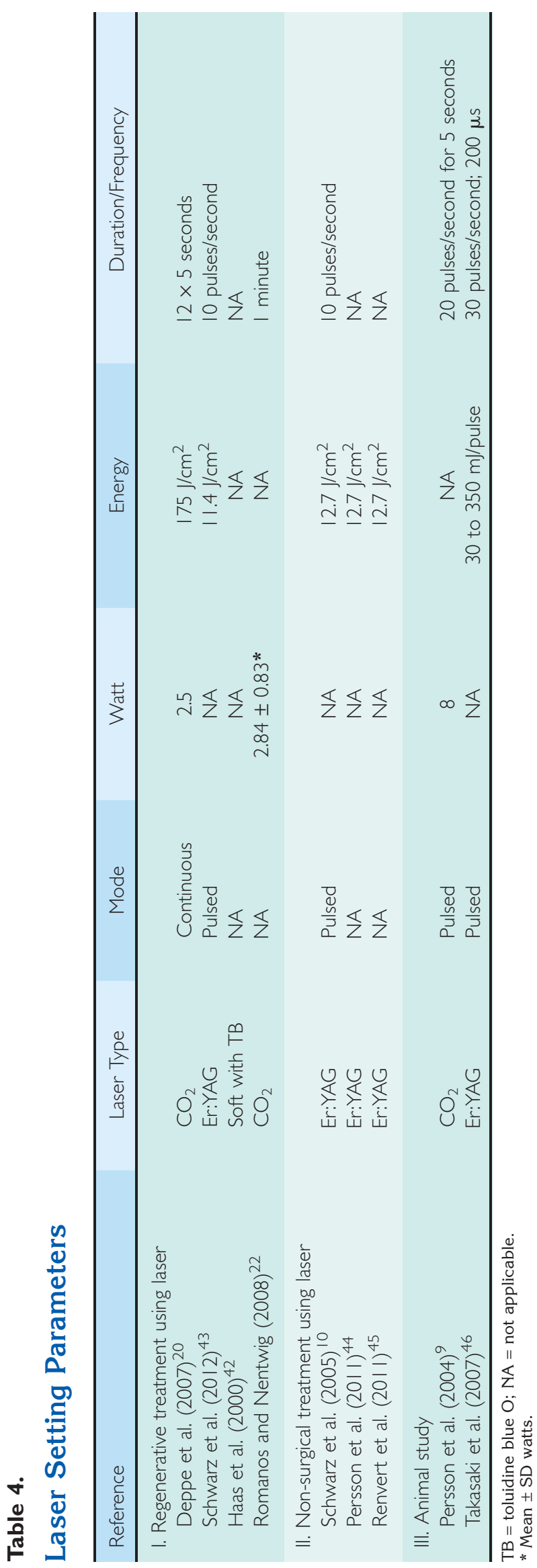

group (WMD $=0.00 \mathrm{~mm}, 95 \% \mathrm{CI}=-0.18$ to 0.19 $\mathrm{mm}, P=0.98)$. This was in agreement with the European Workshop of Periodontology 2008 consensus report, ${ }^{54}$ which stated that, in peri-implantitis lesions, non-surgical therapy was not found to be effective, and only minor effects of laser therapy of peri-implantitis have been shown. It might be hypothesized that the long-term stability of the clinical results obtained in the present study is primarily dependent on proper oral hygiene. ${ }^{13}$ For the surgically treated group, the results could not be compared because of an insufficient number of studies with the same design.

The result of the present study corroborates the previous data analysis reported by Esposito et al. ${ }^{55}$ The authors failed to show any benefit of using an Er:YAG laser over manual debridement with plastic curets and concluded that there was no reliable evidence suggesting which interventions could be most effective for treating peri-implantitis. However, it should not be interpreted that currently used interventions may not be effective. ${ }^{55}$ Khoury and Buchmann ${ }^{17}$ evaluated 41 peri-implant defects in 25 patients treated with flap surgery and citric acid for implant decontamination, followed by GBR procedures. Six months before surgical treatment, all patients received non-surgical therapy, including implant scaling and systemic antimicrobial therapy. Although the study showed that non-surgical therapy resulted in a temporary improvement of the outcome measures because decontamination of the implant surfaces could not be achieved sufficiently, surgical treatment revealed significant changes in PD reduction and intrabony defect fill and mobility score improvement at 3 years postoperatively. ${ }^{17}$ Behneke et al. ${ }^{18}$ also reported positive results of treating peri-implantitis with a surgical approach. ${ }^{18}$ Intrasurgery observations showed that the median defect depth decreased from 6.9 to $0.7 \mathrm{~mm}(P=$ $0.001)$, corresponding to a $90 \%$ bone repair. ${ }^{18}$

Surgical treatment of peri-implantitis using Er:YAG laser versus plastic curets for implant surface decontamination has also been studied. ${ }^{43}$ The results revealed that mean $\mathrm{BOP}, \mathrm{PD}$, and CAL values were significantly reduced in both groups. However, comparisons between groups failed to achieve statistically significant differences in PD and CAL changes at 12 and 24 months $(P>0.05)$. Based on this observation, it might be considered that methods used for surface decontamination were not a crucial factor significantly influencing the outcome of surgical therapy of peri-implantitis. ${ }^{43}$

Limitations of this meta-analysis included inconsistencies in methodologies and treatment modalities, the limited number of RCTs included, the small sample size, short follow-up periods, and heavier 
contributions from the same research group to the results of this meta-analysis.

\section{CONCLUSIONS}

Within the limitations of this study, the following conclusions could be drawn. 1) Research on the effect lasers have when treating peri-implantitis is inadequate; $\mathrm{CO}_{2}$ and Er:YAG lasers are the most studied lasers. 2) Lasers could be an adjunct in the treatment of peri-implantitis; however, the amounts of PD reduction, CAL gain, and radiographic bone fills as a result of the laser therapy seemed identical to other commonly used surface detoxification methods.

\section{ACKNOWLEDGMENTS}

This work was partially supported by the University of Michigan Periodontal Graduate Student Research Fund. The authors report no conflicts of interest related to this study.

\section{REFERENCES}

1. Klinge $B$, Hultin $M$, Berglundh T. Peri-implantitis. Dent Clin North Am 2005;49:661-676, vii-viii.

2. Rosen P, Clem D, Cochran D, et al. Peri-implant mucositis and peri-implantitis: A current understanding of their diagnoses and clinical implications. J Periodontol 2013;84:436-443.

3. Botero JE, González AM, Mercado RA, Olave G, Contreras A. Subgingival microbiota in peri-implant mucosa lesions and adjacent teeth in partially edentulous patients. J Periodontol 2005;76:1490-1495.

4. Shibli JA, Melo L, Ferrari DS, Figueiredo LC, Faveri $M$, Feres M. Composition of supra- and subgingival biofilm of subjects with healthy and diseased implants. Clin Oral Implants Res 2008;19:975-982.

5. Schwarz F, Papanicolau P, Rothamel D, Beck B, Herten M, Becker J. Influence of plaque biofilm removal on reestablishment of the biocompatibility of contaminated titanium surfaces. J Biomed Mater Res A 2006; 77:437-444.

6. Quirynen M, van der Mei HC, Bollen CM, et al. An in vivo study of the influence of the surface roughness of implants on the microbiology of supra- and subgingival plaque. J Dent Res 1993;72:1304-1309.

7. Hämmerle CH, Fourmousis I, Winkler JR, Weigel C, Brägger U, Lang NP. Successful bone fill in late peri-implant defects using guided tissue regeneration. A short communication. J Periodontol 1995; 66:303-308.

8. Schwarz F, Jepsen S, Herten M, Sager M, Rothamel $D$, Becker J. Influence of different treatment approaches on non-submerged and submerged healing of ligature induced peri-implantitis lesions: An experimental study in dogs. J Clin Periodontol 2006;33:584-595.

9. Persson LG, Mouhyi J, Berglundh T, Sennerby L, Lindhe J. Carbon dioxide laser and hydrogen peroxide conditioning in the treatment of periimpantitis: An experimental study in the dog. Clin Implant Dent Relat Res 2004;6:230-238.

10. Schwarz F, Sculean A, Rothamel D, Schwenzer K, Georg T, Becker J. Clinical evaluation of an Er:YAG laser for nonsurgical treatment of peri-implantitis: A pilot study. Clin Oral Implants Res 2005;16:44-52.
11. Roos-Jansåker AM, Renvert S, Egelberg J. Treatment of peri-implant infections: A literature review. $J$ Clin Periodontol 2003;30:467-485.

12. Gosau M, Hahnel S, Schwarz F, Gerlach T, Reichert TE, Bürgers R. Effect of six different peri-implantitis disinfection methods on in vivo human oral biofilm. Clin Oral Implants Res 2010;21:866-872.

13. Ando Y, Aoki A, Watanabe H, Ishikawa I. Bactericidal effect of erbium YAG laser on periodontopathic bacteria. Lasers Surg Med 1996;19:190-200.

14. Aleksic V, Aoki A, Iwasaki K, et al. Low-level Er: YAG laser irradiation enhances osteoblast proliferation through activation of MAPK/ERK. Lasers Med Sci 2010;25:559-569.

15. Schwarz F, Sculean A, Romanos G, et al. Influence of different treatment approaches on the removal of early plaque biofilms and the viability of SAOS2 osteoblasts grown on titanium implants. Clin Oral Investig 2005;9:111-117.

16. Matsuyama T, Aoki A, Oda S, Yoneyama T, Ishikawa I. Effects of the Er:YAG laser irradiation on titanium implant materials and contaminated implant abutment surfaces. J Clin Laser Med Surg 2003;21:7-17.

17. Khoury F, Buchmann R. Surgical therapy of periimplant disease: A 3-year follow-up study of cases treated with 3 different techniques of bone regeneration. J Periodontol 2001;72:1498-1508.

18. Behneke A, Behneke N, d'Hoedt B. Treatment of peri-implantitis defects with autogenous bone grafts: Six-month to 3-year results of a prospective study in 17 patients. Int $J$ Oral Maxillofac Implants 2000; 15:125-138.

19. Cobb CM. Lasers in periodontics: A review of the literature. J Periodontol 2006;77:545-564.

20. Deppe H, Horch HH, Neff A. Conventional versus $\mathrm{CO}_{2}$ laser-assisted treatment of peri-implant defects with the concomitant use of pure-phase beta-tricalcium phosphate: A 5-year clinical report. Int J Oral Maxillofac Implants 2007;22:79-86.

21. Stübinger S, Nuss K, Landes C, von Rechenberg B, Sader R. Harvesting of intraoral autogenous block grafts from the chin and ramus region: Preliminary results with a variable square pulse Er:YAG laser. Lasers Surg Med 2008;40:312-318.

22. Romanos GE, Nentwig GH. Regenerative therapy of deep peri-implant infrabony defects after $\mathrm{CO}_{2}$ laser implant surface decontamination. Int $J$ Periodontics Restorative Dent 2008;28:245-255.

23. Higgins JP, Green S. Cochrane Handbook for Systematic Reviews of Interventions. Version 5.1.0 (updated March 2011). The Cochrane Collaboration, 2011. Available at: http://www.cochrane-handbook.org.

24. Schulz KF, Altman DG, Moher D; CONSORT Group. CONSORT 2010 statement: Updated guidelines for reporting parallel group randomized trials. Ann Intern Med 2010;152:726-732.

25. Liberati A, Altman DG, Tetzlaff J, et al. The PRISMA statement for reporting systematic reviews and metaanalyses of studies that evaluate health care interventions: Explanation and elaboration. $J$ Clin Epidemiol 2009;62:e1-e34.

26. Bach G, Neckel C, Mall C, Krekeler G. Conventional versus laser-assisted therapy of periimpantitis: A five-year comparative study. Implant Dent 2000; 9:247-251.

27. Deppe H, Horch HH, Henke J, Donath K. Periimplant care of ailing implants with the carbon 
dioxide laser. Int $J$ Oral Maxillofac Implants 2001; 16:659-667.

28. Salmeron S, Rezende ML, Consolaro A, et al. Laser therapy as an effective method for implant surface decontamination: A histomorphometric study in rats. J Periodontol 2013;84:641-649.

29. Schwarz F, Olivier W, Herten M, Sager M, Chaker A, Becker J. Influence of implant bed preparation using an Er:YAG laser on the osseointegration of titanium implants: A histomorphometrical study in dogs. J Oral Rehabil 2007;34:273-281.

30. Stübinger S, Henke J, Donath K, Deppe H. Bone regeneration after peri-implant care with the $\mathrm{CO}_{2}$ laser: A fluorescence microscopy study. Int $J$ Oral Maxillofac Implants 2005;20:203-210.

31. Dörtbudak O, Haas R, Bernhart T, Mailath-Pokorny G. Lethal photosensitization for decontamination of implant surfaces in the treatment of peri-implantitis. Clin Oral Implants Res 2001;12:104-108.

32. Hayek RR, Araújo NS, Gioso MA, et al. Comparative study between the effects of photodynamic therapy and conventional therapy on microbial reduction in ligature-induced peri-implantitis in dogs. $J$ Periodontol 2005;76:1275-1281.

33. Ercan E, Arin T, Kara L, Candirli C, Uysal C. Effects of Er,Cr:YSGG laser irradiation on the surface characteristics of titanium discs: An in vitro study. Lasers Med Sci 2014;29:875-880.

34. Giannelli $M$, Bani D, Tani A, et al. In vitro evaluation of the effects of low-intensity Nd:YAG laser irradiation on the inflammatory reaction elicited by bacterial lipopolysaccharide adherent to titanium dental implants. J Periodontol 2009;80:977-984.

35. Haas R, Dörtbudak O, Mensdorff-Pouilly N, Mailath G. Elimination of bacteria on different implant surfaces through photosensitization and soft laser. An in vitro study. Clin Oral Implants Res 1997;8:249-254.

36. Kim JH, Herr Y, Chung JH, Shin SI, Kwon YH. The effect of erbium-doped:yttrium, aluminium and garnet laser irradiation on the surface microstructure and roughness of double acid-etched implants. J Periodontal Implant Sci 2011;41:234-241.

37. Kreisler M, Kohnen W, Marinello C, et al. Bactericidal effect of the Er:YAG laser on dental implant surfaces: An in vitro study. $J$ Periodontol 2002;73: 1292-1298.

38. Yamamoto A, Tanabe T. Treatment of peri-implantitis around TiUnite-surface implants using Er:YAG laser microexplosions. Int $J$ Periodontics Restorative Dent 2013;33:21-30.

39. Schwarz F, Bieling K, Nuesry E, Sculen A, Becker J. Clinical and histological healing pattern of periimplantitis lesions following non-surgical treatment with an Er:YAG laser. Lasers Surg Med 2006;38:663-671.

40. Schwarz F, Sahm N, Iglhaut G, Becker J. Impact of the method of surface debridement and decontamination on the clinical outcome following combined surgical therapy of peri-implantitis: A randomized controlled clinical study. J Clin Periodontol 2011;38:276-284.

41. Landis JR, Koch GG. The measurement of observer agreement for categorical data. Biometrics 1977;33: 159-174.
42. Haas R, Baron M, Dörtbudak O, Watzek G. Lethal photosensitization, autogenous bone, and e-PTFE membrane for the treatment of peri-implantitis: Preliminary results. Int $J$ Oral Maxillofac Implants 2000;15:374-382.

43. Schwarz F, John G, Mainusch S, Sahm N, Becker J. Combined surgical therapy of peri-implantitis evaluating two methods of surface debridement and decontamination. A two-year clinical follow up report. J Clin Periodontol 2012;39:789-797.

44. Persson GR, Roos-Jansåker AM, Lindahl C, Renvert S. Microbiologic results after non-surgical erbiumdoped:yttrium, aluminum, and garnet laser or airabrasive treatment of peri-implantitis: A randomized clinical trial. J Periodontol 2011;82:1267-1278.

45. Renvert S, Lindahl C, Roos Jansåker AM, Persson GR. Treatment of peri-implantitis using an Er:YAG laser or an air-abrasive device: A randomized clinical trial. J Clin Periodontol 2011;38:65-73.

46. Takasaki AA, Aoki A, Mizutani K, Kikuchi S, Oda S, Ishikawa I. Er:YAG laser therapy for peri-implant infection: A histological study. Lasers Med Sci 2007; 22:143-157.

47. Oyster DK, Parker WB, Gher ME. $\mathrm{CO}_{2}$ lasers and temperature changes of titanium implants. J Periodontol 1995;66:1017-1024.

48. Romanos GE, Everts H, Nentwig GH. Effects of diode and Nd:YAG laser irradiation on titanium discs: A scanning electron microscope examination. $J$ Periodontol 2000;71:810-815.

49. Geminiani A, Caton JG, Romanos GE. Temperature change during non-contact diode laser irradiation of implant surfaces. Lasers Med Sci 2012;27:339-342.

50. Aoki A, Sasaki KM, Watanabe H, Ishikawa I. Lasers in non-surgical periodontal therapy. Periodontol 2000 2004;36:59-97.

51. Kato T, Kusakari H, Hoshino E. Bactericidal efficacy of carbon dioxide laser against bacteria-contaminated titanium implant and subsequent cellular adhesion to irradiated area. Lasers Surg Med 1998;23:299-309.

52. Kreisler M, Götz H, Duschner H. Effect of Nd:YAG, Ho:YAG, Er:YAG, CO2, and GaAIAs laser irradiation on surface properties of endosseous dental implants. Int $J$ Oral Maxillofac Implants 2002;17:202-211.

53. Yamaguchi $H$, Kobayashi K, Osada R, et al. Effects of irradiation of an erbium:YAG laser on root surfaces. J Periodontol 1997;68:1151-1155.

54. Lindhe J, Meyle J; Group D of European Workshop on Periodontology. Peri-implant diseases: Consensus report of the Sixth European Workshop on Periodontology. J Clin Periodontol 2008;35(Suppl. 8):282-285.

55. Esposito M, Grusovin MG, Worthington HV. Interventions for replacing missing teeth: Treatment of peri-implantitis. Cochrane Database Syst Rev 2012; 1:CD004970.

Correspondence: Dr. Hom-Lay Wang, 1011 N. University Ave., Ann Arbor, MI 48109-1078. Fax: 734/936-0374; e-mail: homlay@umich.edu.

Submitted October 17, 2013; accepted for publication January 7, 2014. 